\title{
Nowruz travelers and the COVID-19 pandemic in Iran
}

\author{
Amir Kaffashi PhD (1) and Frieda Jahani MSc
}

Razi Vaccine and Serum Research Institute, Agricultural Research, Education and Extension Organization (AREEO), Karaj, Iran

To the Editor-Iran, struggling with the toughest sanctions, is facing serious challenges in containing the pandemic of coronavirus disease 2019 (COVID-19). As of April 9, 2020, some 66,220 confirmed cases and 4,110 deaths had been reported in Iran. ${ }^{1}$ The rise of this pandemic coincided with Nowruz (the Persian New Year) holidays, which started on March 19, 2020, and lasted $\sim 2$ weeks. Millions of Iranians travel around the country during the Nowruz holiday.

Iranian authorities urged people to stay home during Nowruz and announced that public screening to detect coronavirus would be underway at airports, railway stations, bus terminals, and the city entrances and exits. ${ }^{2}$ By March 22, 2020, however, 8,700,000 people in transit and the passengers of $\sim 2,900,000$ cars had been screened using thermal imager and gun thermometers. Among them, 6,464 were referred to clinical centers for further examination. ${ }^{3}$ Given the fact people with no symptoms might have been missed during public screening, a large number of travelers spread the SARS-CoV-2 virus across the country. The implications of virus transmission from persons with asymptomatic or very mild symptomatic cases of COVID-19 has already been considered vital for the formulation of containment strategies. ${ }^{4}$

In a similar situation, the COVID-19 epidemic in China coincided with the peak of the Chinese spring festival holidays. The Chinese government implemented rigorous quarantine measures and locked down the epicenter of the outbreak, Wuhan City, Hubei Province, on January 23, 2020. No new confirmed cases occurred in most provinces across China and in most cities in Hubei Province for $>10$ consecutive days by March 1, 2020, suggesting that the lockdown had been effective in mitigating the spread of the virus. ${ }^{5}$ Apart from social and economic effects, such travel restrictions are considered less effective once the outbreak is more widespread. ${ }^{6}$ By March 9, 2020, COVID-19 cases had been reported in all provinces in Iran, at incidence rates ranging from 0.8 cases per 100,000 population in Bushehr to 61.8 cases per 100,000 population in Qom. ${ }^{7}$ It was already too late for any restriction to be effective.

On March 27, 2020, the Iranian government implemented a travel ban preventing people from leaving their cities and requesting those already on trips to return at their earliest opportunity. ${ }^{8}$ However, a modeling study showed that travel limitations eliminating up to $90 \%$ of the traffic have a modest effect and that such measures should be combined with public health interventions and behavioral changes to achieve a considerable reduction in disease transmission. ${ }^{9}$ The spread of SARS-CoV-2 is not yet slowing down in Iran, and the recommendation of the World Health Organization (WHO) seems more likely to result in the containment of COVID-19. These include widespread testing, quarantine of cases, contact tracing, and social distancing, which were successfully implemented by South Korea. ${ }^{10}$

Financial support. No financial support was provided relevant to this article.

Conflicts of interest. All authors report no conflicts of interest relevant to this article.

\section{References}

1. Officials: COVID 19 death toll hits 4,110 in Iran. Islamic Republic News Agency website. https://en.irna.ir/news/83744712/Official-COVID19-deathtoll-hits-4-110-in-Iran. Published April 9, 2020. Accessed April 10, 2020.

2. Coronavirus screening underway at terminals. Islamic Republic News Agency website. https://en.irna.ir/news/83718096/Coronavirus-screeningunderway-at-terminals. Published March 19, 2020. Accessed March 31, 2020.

3. Coronavirus situation report-3. Iranian Red Crescent website. http://en.rcs. ir/News/s/125646. Published March 22, 2020. Accessed April 10, 2020.

4. Hoehl S, Rabenau H, Berger A, et al. Evidence of SARS-CoV-2 infection in returning travelers from Wuhan, China. N Engl J Med 2020;382:1278-1280.

5. Wang F, Li Y, Tang D, et al. Trend of the coronavirus disease- 2019 epidemic in China after the lockdown of Wuhan City on January 23, 2020. Social Science Research Network website. https://ssrn.com/abstract=3555218. Published March 23, 2020. Accessed April 12, 2020.

6. Kraemer MUG, Yang CH, Gutierrez B, et al. The effect of human mobility and control measures on the COVID-19 epidemic in China. Science 2020 Mar 25 [Epub ahead of print]. doi: 10.1126/science.abb4218.

7. Arab-Mazar Z, Sah R, Rabaan AA, Dhama K, Rodriguez-Morales AJ. Mapping the incidence of COVID-19 hot spots in Iran-implications for travellers. Travel Med Infect Dis 2020 Mar 14 [Epub ahead of print]. doi: 10.1016/j.tmaid.2020.101630.

8. Tough measures to be taken to contain coronavirus outbreak in Iran. Tehran Times website. https://www.tehrantimes.com/news/446310/Toughmeasures-to-be-taken-to-contain-coronavirus-outbreak-in. Published March 25, 2020. Accessed April 10, 2020.

9. Chinazzi M, Davis JT, Ajelli M, et al. The effect of travel restrictions on the spread of the 2019 novel coronavirus (COVID-19) outbreak. Science 2020 Mar 6 [Epub ahead of print]. doi: 10.1126/science.aba9757.

10. Normile D. Coronavirus cases have dropped sharply in South Korea. What's the secret to its success? Science website. https://www.sciencemag.org/news/ 2020/03/coronavirus-cases-have-dropped-sharply-south-korea-whats-secretits-success\#. Published March 17, 2020. Accessed April 10, 2020. 